\title{
In Vitro Immunomodulatory Activity of a Transition-State Analog Inhibitor of Human Purine Nucleoside Phosphorylase in Cutaneous Leishmaniasis
}

\author{
Natália Barbosa Carvalho, ${ }^{1}$ Fernanda Ventin de Oliveira Prates, ${ }^{1}$ Rafael de Castro da Silva, \\ Mayra Elizabeth Ferreira Dourado, ${ }^{1}$ Camila Farias Amorim, ${ }^{1}$ Paulo Roberto Lima Machado, \\ Fernanda Grendene Pacheco, ${ }^{2}$ Temis Weber Furlanetto Corte, ${ }^{2}$ Pablo Machado, ${ }^{2}$ \\ Diógenes Santiago Santos, ${ }^{2}$ and Edgar Marcelino de Carvalho ${ }^{1,3}$ \\ ${ }^{1}$ Serviço de Imunologia do Complexo Hospitalar Universitário Professor Edgard Santos (Com-HUPES), \\ Universidade Federal da Bahia, Salvador, BA, Brazil \\ ${ }^{2}$ Centro de Pesquisas em Biologia Molecular e Funcional (CPBMF), Pontifícia Universidade Católica do Rio Grande do Sul, \\ Porto Alegre, RS, Brazil \\ ${ }^{3}$ Fundação Oswaldo Cruz (FIOCRUZ), Instituto Gonçalo Moniz (CPqGM), Salvador, BA, Brazil
}

Correspondence should be addressed to Edgar Marcelino de Carvalho; imuno@ufba.br

Received 14 May 2017; Accepted 31 July 2017; Published 27 August 2017

Academic Editor: Nejat K. Egilmez

Copyright (C) 2017 Natália Barbosa Carvalho et al. This is an open access article distributed under the Creative Commons Attribution License, which permits unrestricted use, distribution, and reproduction in any medium, provided the original work is properly cited.

\begin{abstract}
Cutaneous leishmaniasis (CL) is the most common clinical form of American tegumentary leishmaniasis caused by Leishmania (Viannia) braziliensis. CL is associated with a strong Th1 immune response. This exacerbated inflammatory response is correlated with severity of disease and delays the healing time of the ulcer. The fourth-generation immucillin derivative (DI4G), a potent inhibitor of purine nucleoside phosphorylase, has been proposed as a promising agent in the treatment of diseases associated with $\mathrm{T}$ cell activation. Herein, we evaluated the in vitro immunomodulatory activity of DI4G in cells of patients presenting with CL. Peripheral blood mononuclear cells (PBMC) from CL patients were stimulated with soluble leishmania antigen (SLA), in the presence or absence of DI4G, and IFN- $\gamma$, TNF, CXCL9, and CXCL10 levels were determined by ELISA. Lymphocyte proliferation in the presence or absence of DI4G was also evaluated, using flow cytometry. DI4G was able to decrease $(p<0.05)$ IFN- $\gamma$ production but did not change the TNF, CXCL9, and CXCL10 levels. DI4G decreased $(p<0.05)$ the lymphoproliferative response mediated by $\mathrm{CD}^{+} \mathrm{T}$ cells, but not that by $\mathrm{CD} 4^{+} \mathrm{T}$ cells. DI4G is able to attenuate the exaggerated immune response in CL, exhibiting immunomodulatory activity in IFN- $\gamma$ production and in $\mathrm{CD} 8^{+} \mathrm{T}$ cell proliferation.
\end{abstract}

\section{Introduction}

Leishmaniasis is a global health problem and it is considered one of the most important neglected tropical diseases. Cutaneous leishmaniasis (CL) is the most common clinical form of American tegumentary leishmaniasis (ATL). It is estimated that 0.7 million to 1.2 million new cases occur worldwide annually [1]. In Latin America, CL is caused mainly by the protozoan Leishmania (Viannia) braziliensis which is transmitted by the bite of infected female phlebotomine sandflies of the genus Lutzomyia [2]. The strong inflammatory response with infiltration of lymphocytes, macrophages, granuloma formation, and small numbers or absence of parasites within skin lesions is a hallmark of CL caused by $L$. braziliensis [3]. The cell-mediated immune response is considered the main defense mechanism against protozoan parasites. However, in CL, both $\mathrm{CD} 4^{+}$and $\mathrm{CD} 8^{+} \mathrm{T}$ cells have been associated with pathology [4-7]. The inflammatory cytokines, such as IFN- $\gamma$ and TNF, are important for control of parasite replication, but an exaggerated Th1 immune 


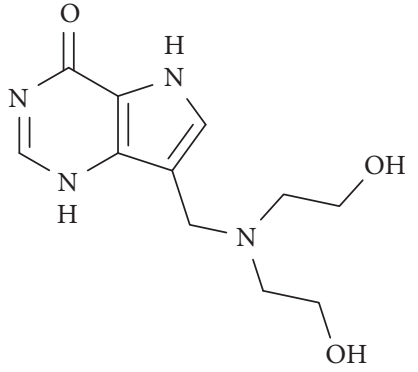

FIGURE 1: Chemical structure of the synthesized fourth-generation immucillin derivative (DI4G).

response observed during $L$. braziliensis infection leads to the development of tissue injury [5, 8-11]. Regarding $\mathrm{CD}^{+} \mathrm{T}$ cells, it was documented that $\mathrm{T}$ cell-mediated cytotoxicity is higher in severe forms of the disease $[12,13]$. Moreover, rather than leishmania killing, cytotoxicity mediated by $\mathrm{CD}^{+} \mathrm{T}$ cells is associated with an intense inflammatory response and killing of parasite-infected cells, rather than leishmania death $[7,13]$.

In Latin America, pentavalent antimony is the first-line drug for treatment of CL. However, a high rate of therapeutic failure has been documented [14-16]. More recently, it has been shown that the association of antimony with immunoregulatory drugs, such as the granulocyte and monocyte colony-stimulating factor (GM-CSF) or pentoxyfilline, a drug that reduces TNF levels, is more effective than antimony alone and reduces the healing time of cutaneous and mucosal leishmaniasis [16-20].

It is well documented that $\mathrm{T}$ cell proliferation and activation is dependent on the purine nucleotide phosphorylase (PNP) enzyme activity. PNP operates in catalyzing reversible phosphorylation of purine nucleoside leading to production of their respective bases and a phosphorylated pentose, an important reaction in the recycling of purines, allowing the synthesis of essential compounds for the high proliferative capacity observed in activated $\mathrm{T}$ cells [21]. The fourthgeneration immucillin derivative DI4G (Figure 1) is a potent transition-state analog inhibitor of human PNP (HsPNP). This compound has been described as competitive inhibitor of HsPNP with $K_{\mathrm{i}}$ of $11.8 \pm 1.47 \mathrm{nM}$ regarding inosine substrate [22]. In addition, DI4G showed an $\mathrm{IC}_{50}$ value of $40.6 \pm 0.36 \mathrm{nM}$ when evaluated at substrate concentrations near to the $K_{\mathrm{M}}$ values for HsPNP [22]. Therefore, as pathology in CL is due to an exaggerated inflammatory response to leishmania antigen, we evaluated in the present study the in vitro immunomodulatory activity of DI4G in CL.

\section{Material and Methods}

2.1. Patients. This study included 15 CL patients followed at the Corte de Pedra's Health Post, in southeast Bahia, Brazil, an area for $L$. braziliensis transmission. Diagnosis of CL was based on the presence of a typical skin ulcer without mucosal involvement, associated with detection of $L$. braziliensis DNA by polymerase chain reaction in biopsied tissue, parasite isolation in culture, or identification of amastigotes in histopathology [23]. Immunologic studies were performed before therapy. The study was approved by the Ethics Committee of the Medical School of Federal University of Bahia and an informed consent was obtained from all participants.

2.2. Fourth-Generation Immucillin Derivative (DI4G). The immucillin derivative DI4G was synthesized according to already described protocol [24]. The compounds had spectroscopic and spectrometric data that were in agreement with the proposed structure.

2.3. Peripheral Blood Mononuclear Cell (PBMC) Culture. Peripheral blood mononuclear cells (PBMCs) from CL patients were obtained from heparinized venous blood by density gradient centrifugation using Ficoll-Hypaque (GE Healthcare Bio-Sciences, Uppsala, Sweden). The cells were cultivated at $3 \times 10^{6}$ cells $/ \mathrm{ml} /$ well into 24 -well plates in RPMI 1640 medium (Gibco BRL, Grand Island, NY), supplemented with $2 \mathrm{mM}$ L-glutamine, $25 \mathrm{mM}$ HEPES, $10 \%$ heat-inactivated fetal bovine serum (Sigma, St. Louis, MO), and $0.05 \%$ gentamicin at $10 \mathrm{mg} / \mathrm{ml}$ (Gibco BRL, Grand Island, NY). PBMCs were cultivated without stimulus, stimulated with soluble leishmania antigen (SLA; $5 \mu \mathrm{g} / \mathrm{ml}$ ), in the presence or absence of DI4G $(300 \mathrm{nM})$, and phytohemagglutinin (PHA, $10 \mu \mathrm{l} / \mathrm{ml}$; Gibco BRL, Grand Island, $\mathrm{NY}$ ) at $37^{\circ} \mathrm{C}$ in an atmosphere of $5 \% \mathrm{CO}_{2}$. Culture supernatants were collected 72 hours after stimulation and stored at $-20^{\circ} \mathrm{C}$ until used for cytokine measurement.

2.4. Cytokine Measurement. IFN- $\gamma$, TNF, CXCL9, and CXCL10 levels were determined in PBMC culture supernatants by enzyme-linked immunosorbent assay (ELISA) using a commercial kit and according to the manufacturer's instructions (BD Biosciences Pharmingen, San Jose, CA, USA).

2.5. Intracellular Cytokine Staining. For intracellular detection of IFN- $\gamma$, PBMCs were adjusted to $4 \times 10^{5}$ cells/well into 96-well plates. The cells were stimulated with SLA $(5 \mu \mathrm{g} / \mathrm{ml})$, SLA plus DI4G $(300 \mathrm{nM})$, or anti-CD3/anti-CD28 $(1 \mu \mathrm{g} / \mathrm{ml}$ and $0.5 \mu \mathrm{g} / \mathrm{ml}$; BD Pharmingen, San Diego, CA) as positive control at $37^{\circ} \mathrm{C}$ for $20 \mathrm{~h}$. Brefeldin A $(10 \mu \mathrm{g} / \mathrm{ml}$; Sigma, St. Louis, MO) was added for the last $4 \mathrm{~h}$ of culture. Cells were then stained for surface markers and intracellular cytokine. Briefly, cells were stained with monoclonal antibodies (antiCD3-FITC, anti-CD4-APC (eBioscience, San Diego, CA), anti-CD56-FITC, anti-CD3-PercP-Cy5.5, and anti-CD8APC (BD Pharmingen, San Diego, CA)) for 20 minutes at $4^{\circ} \mathrm{C}$. Cells were washed, fixed using a $2 \%$ formaldehyde solution, and permeabilized with a $0.5 \%$ saponin solution in phosphate-buffered saline (PBS). Cells were stained with anti-IFN- $\gamma$-PE (eBioscience, San Diego, CA) for 30 minutes at room temperature. Cells were washed with permeabilization solution and resuspended in PBS. Cells $(150,000$ events) were collected using a II FACSCanto flow cytometer (Becton Dickinson, San Jose, CA), and data were analyzed using the FlowJo Software version 7.6 (Tree Star, Ashland, OR). The lymphocyte and NK populations were selected according to size and granularity and analyzed in $\mathrm{CD}^{+}$and $\mathrm{CD}^{-}$gates, respectively. 


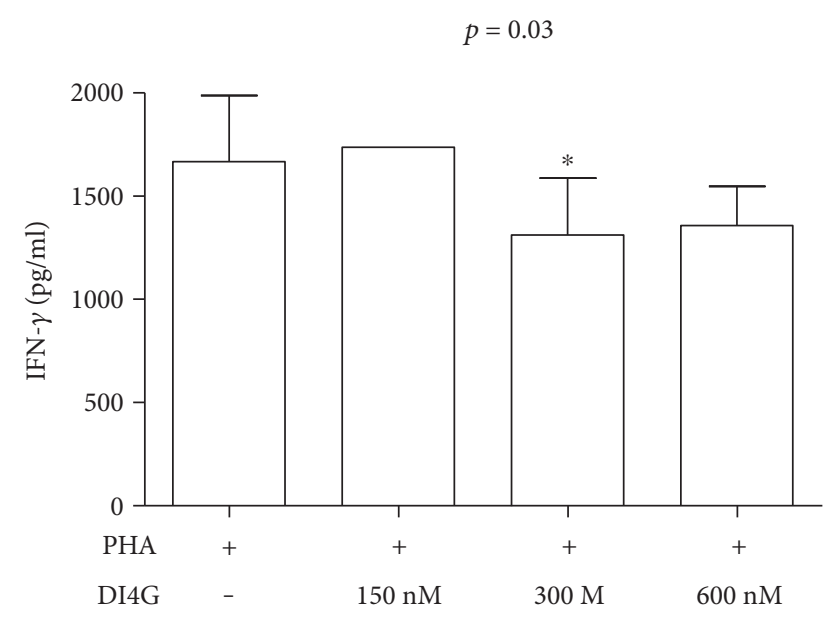

Figure 2: Dose response evaluation of DI4G. PBMCs from healthy individuals $(n=6)$ were stimulated with PHA $(30 \mu \mathrm{l} / \mathrm{ml})$, in the absence and presence of HsPNP inhibitor $(150 \mathrm{nM}, 300 \mathrm{nM}$, and $600 \mathrm{nM}$ ), and levels of IFN- $\gamma$ were determined by ELISA $72 \mathrm{~h}$ poststimulation. Results are presented as means \pm standard deviations. Statistical analyses were performed using Wilcoxon $t$-test $\left({ }^{*} p<0.05\right)$.

2.6. Proliferation Assay. For proliferation assay, PBMCs were cultivated as described above. Six days after culture, cells were stained for surface markers (anti-CD3-FITC (eBioscience, San Diego, CA), anti-CD4-PE, and anti-CD8APC (BD Pharmingen, San Diego, CA)) and intracellularly with anti-Ki-67-PercP-Cy5.5 (BD Pharmingen, San Diego, CA), a cellular marker for proliferation [25]. Cells were then fixed and acquisition and data analysis were performed as described above.

2.7. Statistical Analyses. GraphPad Prism 5 Software (San Diego, CA) was used to carry out the statistical evaluation. $p$ value $<0.05$ was considered to indicate a significant difference. Statistical analyses were performed using Wilcoxon $t$-test.

\section{Results}

3.1. Dose Response Curve to Determine the Optimal Concentration of DI4G. To determine the concentration of DI4G that was capable of impairing cytokine production by activated $\mathrm{T}$ cells, PBMCs from healthy individuals were cultivated with the mitogen PHA $(30 \mu \mathrm{l} / \mathrm{ml})$ in the absence or in the presence of different concentrations of DI4G $(150 \mathrm{nM}, 300 \mathrm{nM}$, and $600 \mathrm{nM})$. The optimal concentration chosen of compound was $300 \mathrm{nM}$ and it rendered $21.3 \%$ reduction in IFN- $\gamma$ production, $p<0.05$ (Figure 2).

3.2. DI4G Impairs IFN- $\gamma$ Production by PBMCs from CL Patients. To evaluate the modulatory action of compound in cellular immune response, PBMCs from CL patients were stimulated with SLA $(5 \mu \mathrm{g} / \mathrm{ml})$, in the presence and absence of HsPNP inhibitor $(300 \mathrm{nM})$, and the levels of IFN- $\gamma$, TNF, CXCL9, and CXCL10 were measured by ELISA. IFN$\gamma$ production by stimulated cells cultured with DI4G was

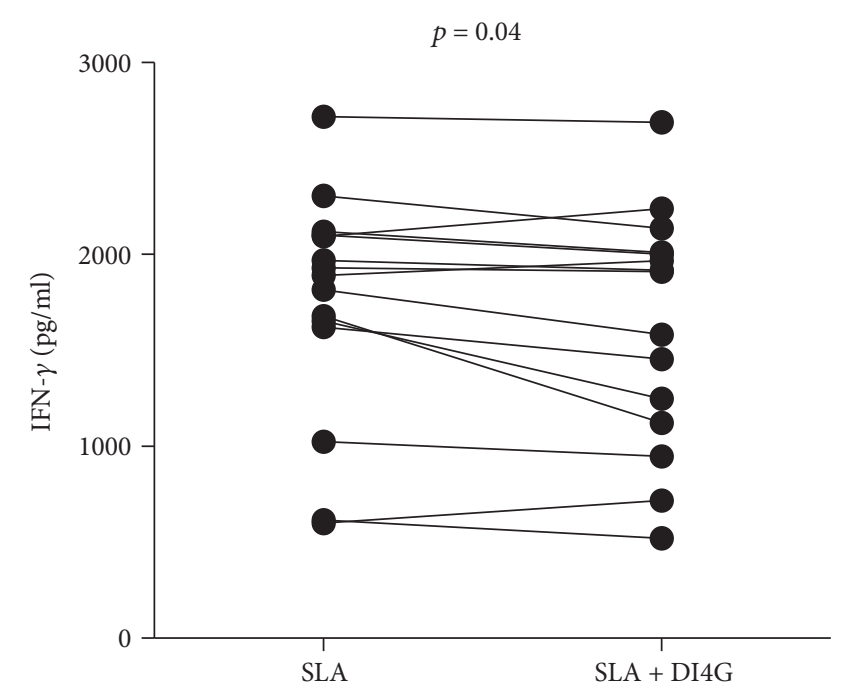

FIgURE 3: Modulatory activity of DI4G in IFN- $\gamma$ production by PBMCs from CL patients. PBMCs from cutaneous leishmaniasis patients $(n=15)$ were cultured with SLA $(5 \mu \mathrm{g} / \mathrm{ml})$, in the absence and presence of compound $(300 \mathrm{nM})$, for $72 \mathrm{~h}$. Levels of IFN- $\gamma$ were determined by ELISA. Statistical analyses were performed using Wilcoxon $t$-test.

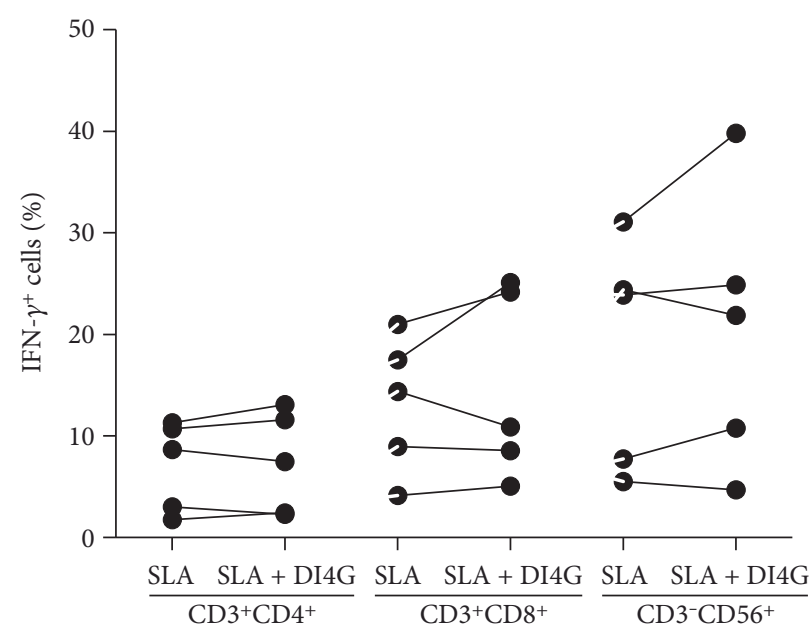

FIGURE 4: Frequencies of IFN- $\gamma$-producing cells from CL patients after SLA and DI4G stimulation. PBMCs from CL patients $(n=5)$ were stimulated with SLA $(5 \mu \mathrm{g} / \mathrm{ml})$, in the absence and presence of compound ( $300 \mathrm{nM})$, for $20 \mathrm{~h}$. Cells were stained for CD3, CD4, CD8, CD56, and IFN- $\gamma$ and collected using II FACSCanto flow cytometer. To analyze the data, the lymphocyte and NK populations were selected according to size and granularity and analyzed in $\mathrm{CD}^{+}$gate and $\mathrm{CD}^{-}$gate, respectively. Statistical analyses were performed using Wilcoxon $t$-test.

lower than that by cells stimulated with only SLA, $p<0.05$ (Figure 3). Overall, there was a $6.4 \%$ reduction in IFN- $\gamma$ production (weighted average, range $0-33 \%$ ), indicating that compound may downmodulate the immune response in cutaneous leishmaniasis. When the production of TNF, CXCL9, and CXCL10 was evaluated, no differences were observed between stimulated cells in the absence and presence of HsPNP inhibitor (data not shown). 


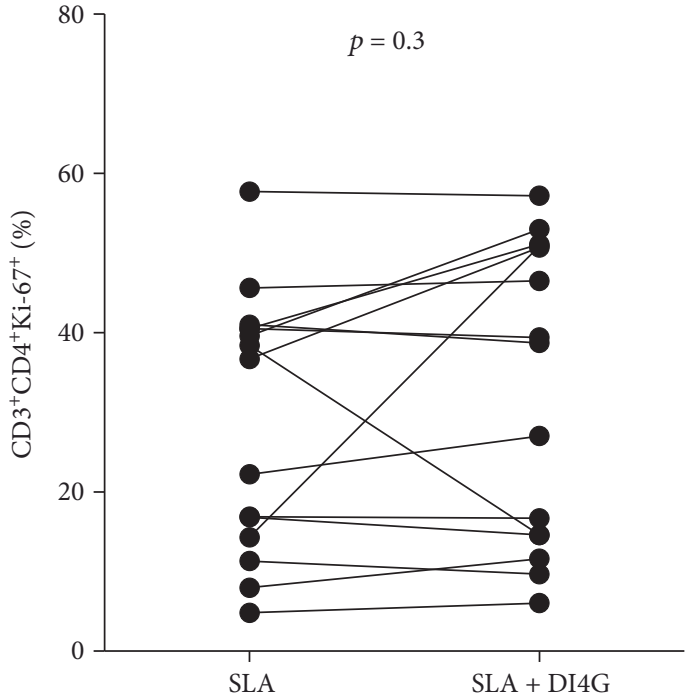

(a)

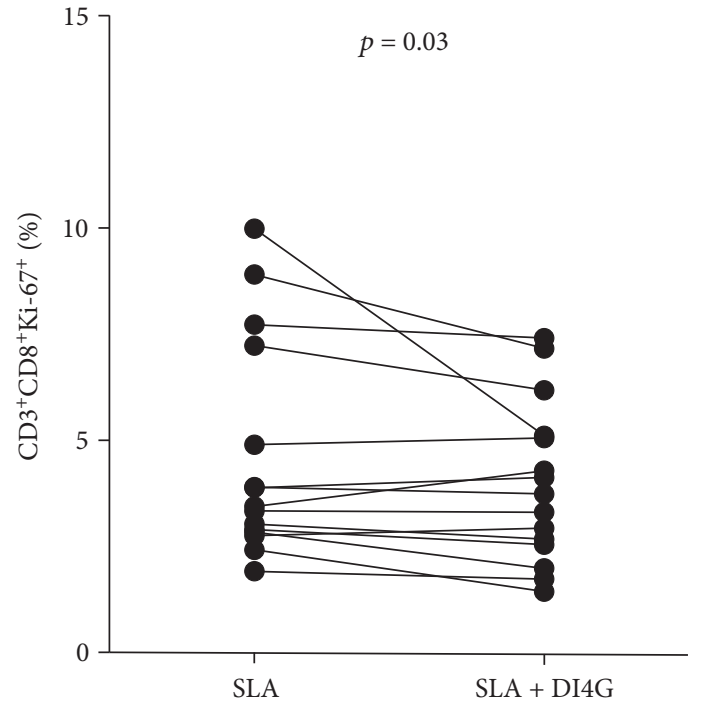

(b)

FIGURE 5: Modulatory activity of DI4G in proliferation of PBMCs from CL patients. PBMCs from cutaneous leishmaniasis patients $(n=15)$ were cultured with SLA $(5 \mu \mathrm{g} / \mathrm{ml})$, in the absence and presence of HsPNP inhibitor $(300 \mathrm{nM})$, for 6 days. CD $4^{+} \mathrm{T}$ cells (a) and CD $8^{+} \mathrm{T}$ cells $(\mathrm{b})$ were stained for CD3, CD4, CD8, and Ki-67 and collected using II FACSCanto flow cytometer. To analyze the data, the lymphocyte populations were selected according to size and granularity and analyzed in $\mathrm{CD}^{+}$gate. Statistical analyses were performed using Wilcoxon $t$-test.

In order to determine the influence of DI4G in IFN- $\gamma$ producing cells, the frequencies of lymphocytes and NK cells expressing this cytokine were determined by flow cytometry. There were no differences in the numbers of $\mathrm{CD} 4^{+}$lymphocytes, $\mathrm{CD} 8^{+}$lymphocytes, and NK cells producing IFN- $\gamma$ in the absence and presence of a molecule (Figure 4).

\subsection{DI4G Is Able to Decrease $C D 8^{+}$Lymphocyte Proliferation} In Vitro from CL Patients. In order to evaluate the action of DI4G in the proliferation of lymphocytes, PBMCs from CL patients were cultured for 6 days with SLA $(5 \mu \mathrm{g} / \mathrm{ml})$, in the presence and absence of compound $(300 \mathrm{nM})$. There was an impairment in the lymphoproliferative response mediated by $\mathrm{CD} 8^{+} \mathrm{T}$ cells, but it was not observed in that by $\mathrm{CD} 4^{+} \mathrm{T}$ cells (Figure 5). Overall, there was a $13.7 \%$ reduction in $\mathrm{CD}^{+} \mathrm{T}$ cell proliferation (weighted average, ranging $0-49 \%$ ).

\section{Discussion}

CL is characterized by one or multiple well-delimited cutaneous ulcers with raised borders [26]. Meglumine antimoniate is the more common therapy for ATL in Latin America and amphotericin is the second choice drug. However, while amphotericin B is associated with important side effects, a high rate of failure has been observed with antimony $[27,28]$. Therefore, new forms of therapy for leishmaniasis are highly desirable. Considering that drugs are able to downmodulate the immune response in combination with a leishmanicidal agent, attenuate pathology, and enhance the cure rate in CL and ML patients, we evaluated in the present study the ability of DI4G, an inhibitor of PNP, to downmodulate the immune response in CL patients. The HsPNP inhibitor significantly decreased IFN- $\gamma$ production in vitro and lymphocyte proliferation of leishmania antigen-stimulated $\mathrm{CD} 8^{+}$lymphocytes from CL patients.

The CL is characterized by an exaggerated production of proinflammatory cytokines produced by $\mathrm{T}$ cells and macrophages $[5,29]$. There is a direct correlation between the frequency of $\mathrm{CD} 4^{+} \mathrm{T}$ cells expressing IFN- $\gamma$ and the lesion size [8] and the frequency of $\mathrm{CD}^{+} \mathrm{T}$ cells expressing granzyme and the inflammatory reaction in CL ulcer [30]. Herein, we showed that DI4G decreased the production of IFN- $\gamma$ in lymphocytes stimulated with leishmania antigen. The influence of this compound in IFN- $\gamma$ was modest but significant. This is of particular interest for two reasons. First, because the exaggerated inflammatory response in CL is due to a decreased ability of regulatory cytokine to downmodulate the immune response. While the regulatory cytokine IL-10 decreased by $86 \%$ the IFN- $\gamma$ production in lymphocyte cultures of tuberculin skin-test-positive healthy subjects stimulated with the $M$. tuberculosis-purified protein derivate (PPD), IL-10 decreased by only $48 \%$ the IFN- $\gamma$ production by cells from CL patients stimulated with leishmania antigen [5]. Second, as IFN- $\gamma$ is important for parasite killing, the downmodulation of this cytokine should be aimed to reduce pathology but preserving the host's ability to control parasite proliferation.

Despite the demonstration that DI4G decreased IFN- $\gamma$ production, when we analyzed if this effect was in $\mathrm{CD} 4^{+} \mathrm{T}$ cells, $\mathrm{CD}^{+} \mathrm{T}$ cells, or NK cells, we did not observe any decrease of IFN- $\gamma$ expression by these cells. As in CL, where one important source of IFN- $\gamma$ production are doublenegative lymphocytes [31], it is possible that the action of the DI4G was in $\mathrm{CD}^{-} \mathrm{CD}^{-}$double-negative T cells.

The pathogenesis of most of the infectious diseases is dependent on both the infectious agent and host factors. In 
protozoa infection, the role of the host immune response in producing tissue damage has been well documented in malaria [32], Chagas disease [33, 34], and ATL [13]. In such case, tissue damage has been associated to a hypersensitivity reaction or to an autoimmunity phenomenon [10,35]. As a decrease in the immune response may favor bacteria, virus, protozoa, and helminthes proliferation, it is important that the modulation of the immune response attenuate pathology, but not impair the defense mechanism.

In ATL, evidences have been accumulated indicating that $\mathrm{T}$ cells and mainly $\mathrm{CD} 8^{+} \mathrm{T}$ cells participate in the pathology of the disease. High lymphocyte proliferation is also characteristic of CL, and we showed that DI4G decreased lymphocyte proliferation predominantly in $\mathrm{CD}^{+} \mathrm{T}$ cells rather than in $\mathrm{CD} 4^{+} \mathrm{T}$ cells. The role of inflammatory and cytotoxic $\mathrm{CD}^{+} \mathrm{T}$ cells in the pathology of CL has been well documented [7, 30, 36, 37]. More recently, evidence has been brought that $\mathrm{CD}^{+} \mathrm{T}$ cells play a key role not only in the inflammatory response and ulcer development but also in the appearance of metastatic lesions in CL [38]. Therefore, it is possible that an exaggerated activation of $\mathrm{CD} 8^{+} \mathrm{T}$ cell is more dangerous for the disease than the inflammatory reaction induced by monocytes and $\mathrm{CD} 4^{+} \mathrm{T}$ cells.

\section{Conclusions}

This study showed that DI4G, a transition-state analog inhibitor of HsPNP, exhibited an immunomodulatory action in IFN- $\gamma$ production by cells from CL patients and decreased $\mathrm{CD}^{+} \mathrm{T}$ cell proliferation, indicating that this agent may be able to reduce pathology associated with $L$. braziliensis infection and can be tested in combination with antimony as a new therapeutic strategy for CL.

\section{Conflicts of Interest}

The authors declare that there is no conflict of interests involved.

\section{Acknowledgments}

The authors are grateful to the staff of the Corte de Pedra Health Post for diagnosis and recruitment of individuals to this study. This work was supported with funding from the Ministry of Health, National Council for Scientific and Technological Development (CNPq) from Brazil (467207/2014-3), and Coordination for the Improvement of Higher Education Personnel (CAPES).

\section{References}

[1] WHO, "Leishmaniasis: worldwide epidemiological and drug access update," World Health Organization, Geneva, Switzerland, 2014, http://www.who.int/leishmaniasis/burden/ Country_profiles/en/.

[2] J. C. Miranda, E. Reis, A. Schriefer et al., "Frequency of infection of Lutzomyia phlebotomines with Leishmania braziliensis in a Brazilian endemic area as assessed by pinpoint capture and polymerase chain reaction," Memórias do Instituto Oswaldo Cruz, vol. 97, no. 2, pp. 185-188, 2002.
[3] A. L. Bittencourt and A. Barral, "Evaluation of the histopathological classifications of American cutaneous and mucocutaneous leishmaniasis," Memórias do Instituto Oswaldo Cruz, vol. 86, no. 1, pp. 51-56, 1991.

[4] L. Soong, C. H. Chang, J. Sun et al., "Role of CD4+ T cells in pathogenesis associated with Leishmania amazonensis infection," Journal of Immunology, vol. 158, no. 11, pp. 53745383, 1997.

[5] O. Bacellar, H. Lessa, A. Schriefer et al., "Up-regulation of Th1type responses in mucosal leishmaniasis patients," Infection and Immunity, vol. 70, no. 12, pp. 6734-6740, 2002.

[6] L. Xin, Y. Li, and L. Soong, "Role of interleukin-1beta in activating the $\mathrm{CD} 11 \mathrm{c}$ (high) $\mathrm{CD} 45 \mathrm{RB}^{-}$dendritic cell subset and priming Leishmania amazonensis-specific $\mathrm{CD} 4^{+} \mathrm{T}$ cells in vitro and in vivo," Infection and Immunity, vol. 75, no. 10, pp. 5018-5026, 2007.

[7] S. Santos Cda, V. Boaventura, C. Ribeiro Cardoso et al., "CD8 ${ }^{+}$ granzyme $\mathrm{B}^{+}$-mediated tissue injury vs. $\mathrm{CD} 4^{+} \mathrm{IFNgamma}^{+}$mediated parasite killing in human cutaneous leishmaniasis," The Journal of Investigative Dermatology, vol. 133, no. 6, pp. 1533-1540, 2013.

[8] L. R. Antonelli, W. O. Dutra, R. P. Almeida, O. Bacellar, E. M. Carvalho, and K. J. Gollob, "Activated inflammatory T cells correlate with lesion size in human cutaneous leishmaniasis," Immunology Letters, vol. 101, no. 2, pp. 226-230, 2005.

[9] D. R. Faria, K. J. Gollob, J. Barbosa Jr. et al., "Decreased in situ expression of interleukin-10 receptor is correlated with the exacerbated inflammatory and cytotoxic responses observed in mucosal leishmaniasis," Infection and Immunity, vol. 73, no. 12, pp. 7853-7859, 2005.

[10] L. P. Carvalho, S. Passos, A. Schriefer, and E. M. Carvalho, "Protective and pathologic immune responses in human tegumentary leishmaniasis," Frontiers in Immunology, vol. 3, p. 301, 2012.

[11] P. Scott and F. O. Novais, "Cutaneous leishmaniasis: immune responses in protection and pathogenesis," Nature Reviews Immunology, vol. 16, no. 9, pp. 581-592, 2016.

[12] C. I. Brodskyn, A. Barral, V. Boaventura, E. Carvalho, and M. Barral-Netto, "Parasite-driven in vitro human lymphocyte cytotoxicity against autologous infected macrophages from mucosal leishmaniasis," Journal of Immunology, vol. 159, no. 9, pp. 4467-4473, 1997.

[13] T. M. Cardoso, A. Machado, D. L. Costa et al., "Protective and pathological functions of $\mathrm{CD}^{+} \mathrm{T}$ cells in Leishmania braziliensis infection," Infection and Immunity, vol. 83, no. 3, pp. 898-906, 2015.

[14] S. E. O'Neal, L. H. Guimaraes, P. R. Machado et al., "Influence of helminth infections on the clinical course of and immune response to Leishmania braziliensis cutaneous leishmaniasis," The Journal of Infectious Diseases, vol. 195, no. 1, pp. 142148, 2007.

[15] A. Llanos-Cuentas, G. Tulliano, R. Araujo-Castillo et al., "Clinical and parasite species risk factors for pentavalent antimonial treatment failure in cutaneous leishmaniasis in Peru," Clinical Infectious Diseases, vol. 46, no. 2, pp. 223-231, 2008.

[16] P. R. Machado, H. Lessa, M. Lessa et al., "Oral pentoxifylline combined with pentavalent antimony: a randomized trial for mucosal leishmaniasis," Clinical Infectious Diseases, vol. 44, no. 6, pp. 788-793, 2007.

[17] J. B. Santos, A. R. de Jesus, P. R. Machado et al., "Antimony plus recombinant human granulocyte-macrophage colony- 
stimulating factor applied topically in low doses enhances healing of cutaneous leishmaniasis ulcers: a randomized, double-blind, placebo-controlled study," The Journal of Infectious Diseases, vol. 190, no. 10, pp. 1793-1796, 2004.

[18] R. P. Almeida, J. Brito, P. L. Machado et al., "Successful treatment of refractory cutaneous leishmaniasis with GM-CSF and antimonials," The American Journal of Tropical Medicine and Hygiene, vol. 73, no. 1, pp. 79-81, 2005.

[19] G. Sadeghian and M. A. Nilforoushzadeh, "Effect of combination therapy with systemic glucantime and pentoxifylline in the treatment of cutaneous leishmaniasis," International Journal of Dermatology, vol. 45, no. 7, pp. 819-821, 2006.

[20] H. A. Lessa, P. Machado, F. Lima et al., "Successful treatment of refractory mucosal leishmaniasis with pentoxifylline plus antimony," The American Journal of Tropical Medicine and Hygiene, vol. 65, no. 2, pp. 87-89, 2001.

[21] A. Bzowska, E. Kulikowska, and D. Shugar, "Purine nucleoside phosphorylases: properties, functions, and clinical aspects," Pharmacology \& Therapeutics, vol. 88, no. 3, pp. 349-425, 2000.

[22] M. C. de Moraes, R. G. Ducati, A. J. Donato et al., "Capillary bioreactors based on human purine nucleoside phosphorylase: a new approach for ligands identification and characterization," Journal of Chromatography. A, vol. 1232, pp. 110-115, 2012.

[23] J. L. Weirather, S. M. Jeronimo, S. Gautam et al., "Serial quantitative PCR assay for detection, species discrimination, and quantification of Leishmania spp. in human samples," Journal of Clinical Microbiology, vol. 49, no. 11, pp. 3892-3904, 2011.

[24] T. Semeraro, A. Lossani, M. Botta et al., "Simplified analogues of immucillin-G retain potent human purine nucleoside phosphorylase inhibitory activity," Journal of Medicinal Chemistry, vol. 49, no. 20, pp. 6037-6045, 2006.

[25] A. Soares, L. Govender, J. Hughes et al., "Novel application of Ki67 to quantify antigen-specific in vitro lymphoproliferation," Journal of Immunological Methods, vol. 362, no. 1-2, pp. 43-50, 2010.

[26] E. A. Llanos Cuentas, C. C. Cuba, A. C. Barreto, and P. D. Marsden, "Clinical characteristics of human Leishmania braziliensis braziliensis infections," Transactions of the Royal Society of Tropical Medicine and Hygiene, vol. 78, no. 6, pp. 845-846, 1984.

[27] T. Newlove, L. H. Guimaraes, D. J. Morgan et al., “Antihelminthic therapy and antimony in cutaneous leishmaniasis: a randomized, double-blind, placebo-controlled trial in patients co-infected with helminths and Leishmania braziliensis," The American Journal of Tropical Medicine and Hygiene, vol. 84, no. 4, pp. 551-555, 2011.

[28] G. Brito, M. Dourado, L. Polari et al., "Clinical and immunological outcome in cutaneous leishmaniasis patients treated with pentoxifylline," The American Journal of Tropical Medicine and Hygiene, vol. 90, no. 4, pp. 617-620, 2014.

[29] A. Giudice, C. Vendrame, C. Bezerra et al., "Macrophages participate in host protection and the disease pathology associated with Leishmania braziliensis infection," BMC Infectious Diseases, vol. 12, p. 75, 2012.

[30] D. R. Faria, P. E. Souza, F. V. Duraes et al., "Recruitment of $\mathrm{CD}^{+} \mathrm{T}$ cells expressing granzyme $\mathrm{A}$ is associated with lesion progression in human cutaneous leishmaniasis," Parasite Immunology, vol. 31, no. 8, pp. 432-439, 2009.
[31] R. L. Bottrel, W. O. Dutra, F. A. Martins et al., "Flow cytometric determination of cellular sources and frequencies of key cytokine-producing lymphocytes directed against recombinant LACK and soluble leishmania antigen in human cutaneous leishmaniasis," Infection and Immunity, vol. 69, no. 5, pp. 3232-3239, 2001.

[32] N. H. Hunt, J. Golenser, T. Chan-Ling et al., "Immunopathogenesis of cerebral malaria," International Journal for Parasitology, vol. 36, no. 5, pp. 569-582, 2006.

[33] L. Higuchi Mde, L. A. Benvenuti, M. Martins Reis, and M. Metzger, "Pathophysiology of the heart in Chagas' disease: current status and new developments," Cardiovascular Research, vol. 60, no. 1, pp. 96-107, 2003.

[34] J. A. Marin-Neto, E. Cunha-Neto, B. C. Maciel, and M. V. Simoes, "Pathogenesis of chronic Chagas heart disease," Circulation, vol. 115, no. 9, pp. 1109-1123, 2007.

[35] E. Cunha-Neto, P. C. Teixeira, L. G. Nogueira, and J. Kalil, "Autoimmunity," Advances in Parasitology, vol. 76, pp. 129$152,2011$.

[36] M. L. Dantas, J. C. Oliveira, L. Carvalho et al., "CD8+ T cells in situ in different clinical forms of human cutaneous leishmaniasis," Revista da Sociedade Brasileira de Medicina Tropical, vol. 46, no. 6, pp. 728-734, 2013.

[37] F. O. Novais, A. M. Carvalho, M. L. Clark et al., "CD8 ${ }^{+}$T cell cytotoxicity mediates pathology in the skin by inflammasome activation and IL-1beta production," PLoS Pathogens, vol. 13, no. 2, article e1006196, 2017.

[38] F. O. Novais, L. P. Carvalho, J. W. Graff et al., "Cytotoxic $\mathrm{T}$ cells mediate pathology and metastasis in cutaneous leishmaniasis," PLoS Pathogens, vol. 9, no. 7, article e1003504, 2013. 


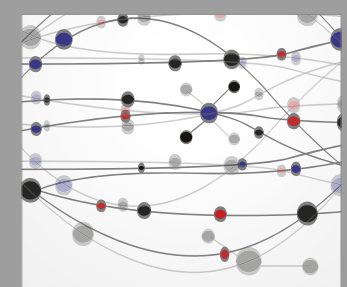

The Scientific World Journal
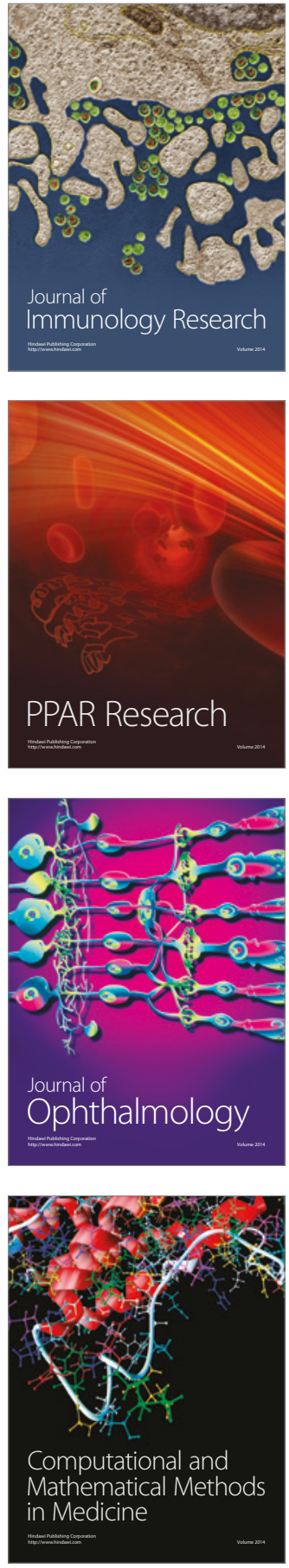

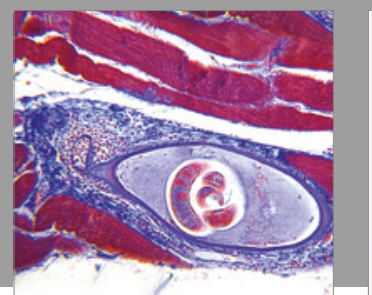

Gastroenterology Research and Practice
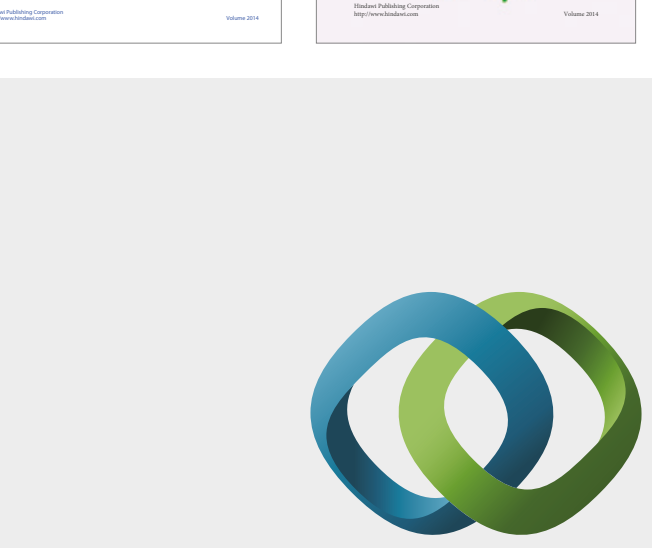

\section{Hindawi}

Submit your manuscripts at

https://www.hindawi.com
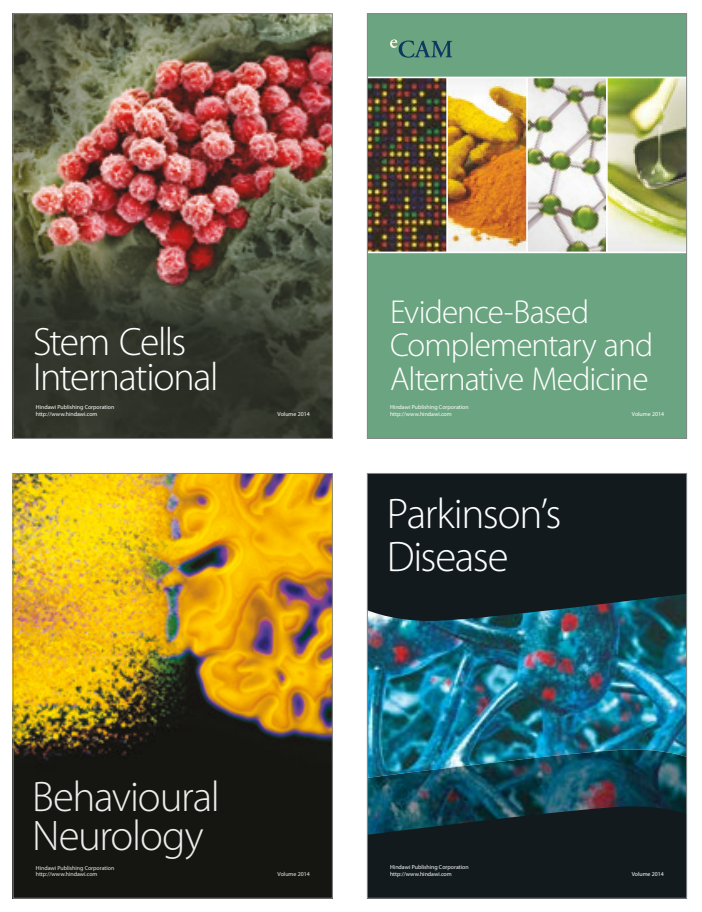
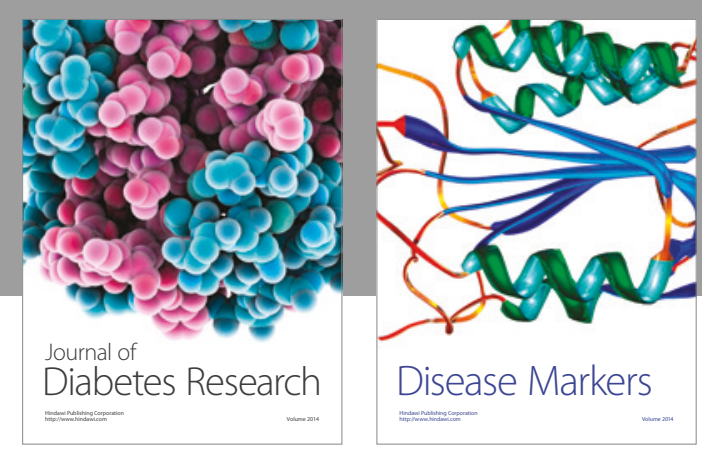

Disease Markers
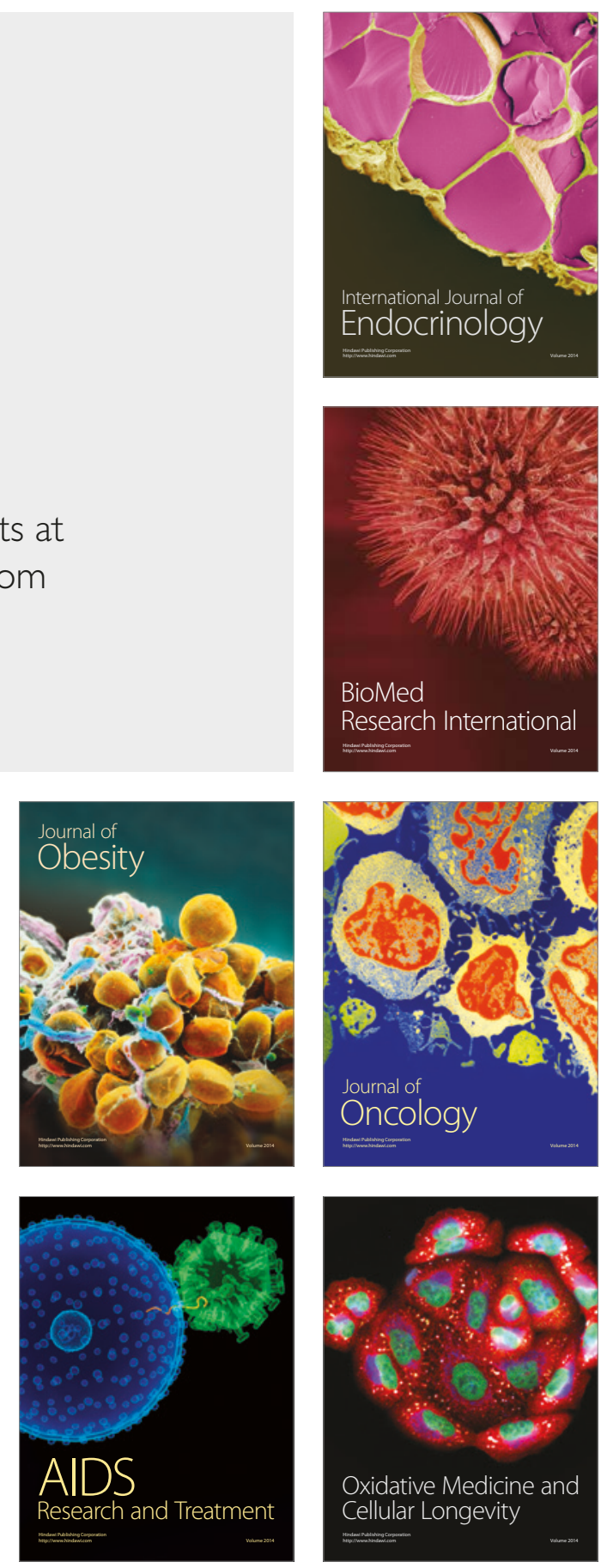